\title{
Effect of length of time post-mortem on quality and freezing capacity of Cantabric chamois (Rupicapra pyrenaica parva) epididymal spermatozoa
}

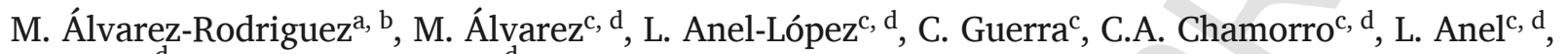 \\ P. de Paz ${ }^{\mathrm{d}}$, e, F. Martínez-Pastor ${ }^{\mathrm{d}}$, e, $*$ \\ ${ }^{a}$ Department of Clinical and Experimental Medicine (IKE), BKH, Obstetrics and Gynecology, Linköping University, Linköping, Sweden \\ ${ }^{\mathrm{b}}$ Department of Animal Health and Anatomy, Veterinary Faculty, Universitat Autònoma de Barcelona, Barcelona, Spain \\ ${ }^{\mathrm{c}}$ Department of Medicine, Surgery and Veterinary Anatomy, Universidad de León, León, Spain \\ d INDEGSAL, Universidad de León, 24071 León, Spain \\ e Department of Molecular Biology (Cell Biology), Universidad de León, Spain
}

\section{ART I C LE INFO}

\section{Keywords:}

Cantabric chamois

Cryopreservation

Epididymal sperm

Post-mortem time

Germplasm banking

\begin{abstract}
A B S T R A C T
Genome Resource Banks are keystones in the ex-situ conservation of wild species. Post-mortem (PM) collection of epididymal spermatozoa is an opportunistic and valuable source of germplasm, the time from the death of the animal limits its use. Seeking to improve germplasm preservation strategies for the chamois (Rupicapra sp.), the effect of PM time on epididymal sperm quality and freezability was studied using the Cantabrian chamois. Samples were classified according to PM collection time, up to $216 \mathrm{~h}$ (refrigerated), and cryopreserved (Tris-citric acid-fructose, $430 \mathrm{mOsm} / \mathrm{kg}, 15 \%$ egg yolk, $8 \%$ glycerol; freezing at $-20^{\circ} \mathrm{C} / \mathrm{min}$ ). Sperm quality was assessed after recovery and post-thawing (motility by CASA, HOS test, abnormal forms, cytoplasmic droplets, and viability and acrosomal damage by flow cytometry). The sperm mass $\mathrm{pH}$ and osmolality showed a positive correlation with time. Total sperm motility dropped after 2 days $\mathrm{PM}$, with progressivity and sperm velocities remained similar up to 3 days PM. Sperm freezability was acceptable, with the post-thawing HOST, motility, progressivity, VAP, VCL, VSL and BCF negatively correlating with PM time. Overall, chamois epidydimal samples were not adequate for preservation after 6 days PM. Freezability capacity could make these spermatozoa suitable for specific ART even if kept refrigerated for several days PM.
\end{abstract}

\section{Introduction}

Genome resource banks (GRB) have become important for the conservation of endangered species or for valuable individuals, and its application requires species-specific cryopreservation protocols. The GRBs allow the preservation of wild species, not only those currently endangered, but also those threatened or at future risk (Holt and Pickard, 1999), allowing the use of the germplasm in assisted reproduction techniques (Prieto et al., 2014). Semen banks are a widespread type of GRB allowing for the preservation of male gametes. The fundamental steps for the establishment of a sperm bank for a wild species are (i) the collection of spermatozoa from the males, (ii) sperm cryopreservation, and (iii) frozen storage of the sperm doses until needed. In this regard, post-mortem epididymal spermatozoa is a convenient source of germplasm and thus allowing for the conservation of genetics (or genetic profiles)

\footnotetext{
* Corresponding author at: INDEGSAL, University of León, Campus de Vegazana, 24071 León, Spain.

Email address: felipe.martinez@unileon.es (F. Martínez-Pastor)
} 
from animals that have recently died or from hunted animals. Spermatozoa collected from the cauda epididymis have desirable maturity and functionality characteristics (Turner, 1995) and thus can be readily used in artificial insemination (AI) programs (Foote, 2000).

At present, the two chamois species (R. pyrenaica and R. rupicapra) are in the Least Concern status of the IUCN Red List of Threatened Species, whereas many of its subspecies are listed as 'Vulnerable' ( $R$. p. ornata and R. r. cartusiana) or 'Critically Endangered' (R. r. tatrica). Furthermore, small populations of the Least Concern subspecies are threatened by human activities and especially by parasitic and viral diseases (Marco et al., 2007, 2008). It, therefore, is believed that this species should be targeted for the banking of germplasm to safeguard against any future catastrophic event to, or rapid decrease in the population.

The time between the death of the animal and the cryopreservation of the sperm sample (post-mortem time) is an important factor for the usability of epididymal samples. Acceptable quality, however, has been obtained from wild ruminant samples stored for several days (red deer: Fernandez-Santos et al., 2009; Spanish ibex: Fernández-Santos et al., 2011; mouflon and fallow deer: Bóveda et al., 2018, studies in deer (Soler and Garde, 2003) and ram samples also had a reduced fertility after only several hours post-mortem (Kaabi et al., 2003). A recent report has described some aspects of the chamois male reproductive system (Carluccio et al, 2007). The effect of seasonality on the genitalia and the quality of epididymal spermatozoa have also been studied (Martínez-Pastor et al., 2005d). The effects of time elapse post-mortem, however, have been thoroughly examined in other wild ruminants (Martínez-Pastor et al., 2005a,c, Martínez et al., 2008; Soler and Garde, 2003) but have not yet been explored in this species.

Furthermore, the cryopreservation of chamois spermatozoa, critical for the establishment of sperm banks, has been described only in a study with semen obtained by trans-rectal ultrasonic-guided massage of the accessory sex glands (TUMASG) (Pradiee et al., 2016). There, therefore, is no information on the effect of post-mortem time in sperm freezability (sperm quality change after cryopreservation).

Thus, in the present study, the aim was to evaluate the effect of post-mortem time on epididymal sperm quality and freezability on the Cantabrian chamois (R. p. parva). To the best of our knowledge, this is the first study to systematically explore the effect of the post-mortem time on chamois epidydimal spermatozoa, and to describe the cryopreservation of this kind of sample and the effect of the post-mortem time on the freezability of its spermatozoa.

\section{Material and methods}

\subsection{Reagents}

All chemicals were acquired from Sigma (Sigma-Aldrich, Stationsplein, Netherlands). Flow cytometry consumables were purchased from Becton Dickinson (Franklin Lakes, NJ, USA). Media were prepared in the laboratory of the manuscript authors as described.

\subsection{Animals and genitalia collection}

Genitalia were collected from Cantabrian chamois ( $R$. pyrenaica parva) collected during the breeding season (October and November) in the hunting reserves of Ancares, Mampodres and Picos de Europa (León, Spain). Animal age was 3-10 years old (7.3 \pm 2.9 SD). The harvest plans followed Law 4/96 of Castilla y León, conforming to European Union regulations. The gamekeepers collected the genital tissues of the harvested animals (complete scrotum with testicles, epididymides and vasa deferentia within) and transported the samples to the researchers, who did not contact the animals in any case. The genitalia were refrigerated as soon as possible after death and processed at different times post-mortem. The interval between the animal death and refrigeration was dutifully noted $(3.4 \pm 1.7 \mathrm{~h}$, no significant effect as a covariate). The researchers ascertained whether the refrigerator temperatures were maintained at $4-5{ }^{\circ} \mathrm{C}$ and the samples were transported to the laboratory at the same temperature.

For sperm collection, the epididymides were isolated, removing all the extraneous tissue, and thoroughly cleaned. The superficial blood vessels of the cauda were punctured and squeezed to remove as much blood as possible. The cauda was then progressively cut with a scalpel, gently squeezing it and collecting the emerging sperm mass with the blade (Martínez-Pastor et al., 2006b), The sperm mass from both epididymides was pooled. All procedures were conducted at $5{ }^{\circ} \mathrm{C}$ in a walk-in refrigerator.

\subsection{Sperm cryopreservation}

The concentration of each sample (spermatozoa/mL) was assessed using a Bürker counting chamber, after diluting the sample in a glutaraldehyde solution [ $5 \mu \mathrm{L}$ of sample in $500 \mu \mathrm{L}$ of $2 \%$ glutaraldehyde solution (glucose monohydrate $146 \mathrm{mM}$, sodium citrate tribasic $34 \mathrm{mmol} / \mathrm{L}$ and sodium bicarbonate $24 \mathrm{mmol} / \mathrm{L})$ ].

A Salamon's modified solution (Tris $222 \mathrm{mM}$, citric acid $73 \mathrm{mM}$ and fructose $55 \mathrm{mM}, 430 \mathrm{mOsm} / \mathrm{kg}$ and $\mathrm{pH} 7$, TCF) was used as buffer solution for preparing the cryopreservation extender (Salamon and Maxwell, 2000). This buffer was supplemented with 15\% egg yolk and 8\% glycerol.

The sperm mass (always at $5^{\circ} \mathrm{C}$ ) was diluted with the same volume of extender and after $2 \mathrm{~h}$ to $100 \times 10^{6} \mathrm{spermatozoa} / \mathrm{mL}$ and then packed in $0.25 \mathrm{~mL}$ French straws. Freezing was conducted using a programmable biofreezer (Kryo-10-16 II Planer TM) at $-20{ }^{\circ} \mathrm{C} /$ min down to $-100^{\circ} \mathrm{C}$ and then transferred to liquid nitrogen containers. Thawing was performed by dropping the straws in circulating water at $65^{\circ} \mathrm{C}$ for $6 \mathrm{~s}$. Samples were analysed 15 min after thawing. 
Fresh samples were evaluated and considered of good quality when all progressive motility, HOS test reactivity and acrosomal status were greater than 60\%, and considered acceptable when greater than 30\% (Martínez-Pastor et al., 2005d).

\subsection{Sperm motility assessment}

Samples were diluted $\left(20 \times 10^{6} \mathrm{~mL}^{-1}\right)$ in Hepes buffer $(20 \mathrm{mmol} / \mathrm{L} \mathrm{Hepes,} 197 \mathrm{mmol} / \mathrm{L} \mathrm{NaCl}, 2.5 \mathrm{mmol} / \mathrm{L} \mathrm{KOH}$, $10 \mathrm{mmol} / \mathrm{L} \mathrm{glu}-$ cose; pH $7.4 \mathrm{mOsm} / \mathrm{kg})$. There was examination of a $5 \mu \mathrm{L}$ drop in a Makler chamber $\left(10 \mu \mathrm{m}\right.$ depth; $\left.37^{\circ} \mathrm{C}\right)$ with a negative phase contrast microscope (Nikon Labophot-2; Nikon, Tokio, Japan). Sperm tracks were obtained by using a CASA system (Motility Analyzer v. $7.4 \mathrm{G}$, Hamilton-Thorne Research, Beverly, MA, USA) in five different fields at $\times 200$ (25 frames/s in $0.8 \mathrm{~s}$ ): VCL (curvilinear path velocity), VSL (straight path velocity), VAP (average path velocity according to the average—smoothed-path; $\mu \mathrm{m} / \mathrm{s}$ ), LIN (linearity), STR (straightness), WOB (wobble), ALH (amplitude of the lateral displacement of the sperm head), and BCF (frequency of the flagellar beat). Total motility (MOT) was set as VCL $>10 \mu \mathrm{m} / \mathrm{s}$ ), and progressive motility (PROG) as VAP $>25 \mu \mathrm{m} / \mathrm{s}$ and STR $>80 \%$ ). Total motility (percentage of cells exhibiting any kind of movement) and progressive motility (percentage of cells with straight movement) were also estimated subjectively in the same session.

\subsection{Hypoosmotic swelling test (HOS test)}

The functional integrity of the sperm plasma membrane was evaluated using the hypoosmotic swelling test (HOS test). A sample $(5 \mu \mathrm{L})$ was diluted in $500 \mu \mathrm{L}$ of a hypoosmotic sodium citrate solution $(100 \mathrm{mOsm} / \mathrm{kg})$. After $18 \mathrm{~min}$ at room temperature $\left(20-22{ }^{\circ} \mathrm{C}\right)$, samples were then fixed with a $20-\mu 1$ drop of glutaraldehyde solution ( $25 \%$ in water). Response to the test was determined by counting 100 cells with a phase-contrast microscope $(400 \times)$. The percentage of positive cells (those with a swollen flagella) was recorded for each sample.

\subsection{Abnormal forms}

Aliquots of the samples were fixed in a glutaraldehyde solution $(5 \mu \mathrm{L}$ in $500 \mu \mathrm{L} ; 2 \%$ glutaraldehyde in an aqueous solution of $146 \mathrm{mmol} / \mathrm{L}$ glucose, $34 \mathrm{mmol} / \mathrm{L}$ sodium citrate tribasic and $24 \mathrm{mmol} / \mathrm{L}$ sodium bicarbonate). A sample ( $5 \mu \mathrm{L})$ was placed on a microscope slide, covered with a coverslip and observed with a phase contrast microscope $(\times 400)$. There were 100 cells assessed, and there was a recording of the proportion of abnormal spermatozoa. Cytoplasmic droplets were considered separately, identifying spermatozoa with proximal (attached or close to the head) or distal (by the limit of the midpiece and tail).

\subsection{Sperm viability and acrosomal damage}

Samples were diluted in buffered media (1:100, the same composition as the one used for motility analysis), and stained with prodidium ioide (PI; $25 \mu \mathrm{g} / \mathrm{L}$ ) and peanut agglutinin lectin conjugated with fluorescein isotiocyanate (PNA-FITC; $1 \mu \mathrm{g} / \mathrm{mL}$ ). After $10 \mathrm{~min}$, the samples were analysed using a FACSCalibur flow cytometer (Becton Dickinson, Franklin Lakes, NJ, USA). Fluorochromes were excited with a $488 \mathrm{~nm}$ argon-laser a $650 \mathrm{LP}$ filter for detecting the red emission light of PI (650 long pass filter), and a 530/30 BP filter for the green emission light of FITC. The proportion of viable spermatozoa (PI-: Viability) and the proportion of damaged acrosomes (PNA+: Acrosomal damage) were determined.

\subsection{Statistical analysis}

The R statistical package ( $\mathrm{R}$ Core Team) was used for data analysis using linear mixed-effects models. The extenders were included as fixed effects and the male as the grouping factor in the random part of the model. Pairwise comparisons were adjusted by Holm's. The effect of the post-mortem time in both fresh and thawed samples was studied by Pearson correlations and by linear models. The comparison between fresh and post-thawing results was conducted using linear mixed-effects models, with group (fresh and post-thawed) as the fixed effect and male as the grouping factor in the random part of the model. Sperm freezability was defined as the difference between fresh and post-thawed values for percentages, and as the ratio of the differences with respect to the fresh value. Results are presented as means \pm SEM, and the threshold for significance was set at $P<0.05$. A classification of the samples was conducted with consideration of the sample quality-following the procedures of Martínez-Pastor et al. (2005d): High quality if motility, HOS test and the acrosomal status were $\geq 60 \%$, medium quality if any of these was less than $60 \%$ but all $\geq 30 \%$, and low quality if any of these was less than $30 \%$.

\section{Results}

A total of 63 genital samples was collected for this study, of which 57 were considered to be in acceptable condition for sperm collection. The basic values for variables of the spermatozoa collected from the cauda epididymides are included in Table 1 . The data for samples collected shortly after the death of the animals indicated there was a highly acceptable recovery and quality, with samples have a slightly acid $\mathrm{pH}$ and an osmolality of about $400 \mathrm{mOsm} / \mathrm{kg}$. In samples collected as duration post-mortem times increased, there was a decreasing motility and membrane functionality (HOS test) as duration of time lengthened, but the changes 
Table 1

Characteristics of collected Cantabrian chamois epididymal spermatozoa in each time interval (mean \pm SEM); Last column $r$ shows the correlation coefficient of each parameter with the post-mortem time; Asterisks indicate differences $\left({ }^{*} P<0.05,{ }^{* *} P<0.01,{ }^{* * *} P<0.001\right.$ ) of the effect of each post-mortem interval (baseline at $[6$, 24] h) and of the correlation coefficient $r$.

\begin{tabular}{|c|c|c|c|c|c|c|c|c|}
\hline $\mathrm{PM}$ intervals $(\mathrm{h})^{\mathrm{a}}$ & {$[6,24]$} & {$[24,48]$} & {$[48,72]$} & {$[72,96]$} & {$[96,144]$} & {$[144,216]$} & $>216$ & \\
\hline Analysed samples & 5 & 4 & 13 & 11 & 10 & 6 & 8 & $r$ \\
\hline $\begin{array}{l}\text { Spermatozoa } \\
\qquad\left(\times 10^{6} / \mathrm{mL}\right)\end{array}$ & $\begin{array}{l}3793.6 \\
\pm 1020.9\end{array}$ & $\begin{array}{l}3201.1 \\
\pm 565.8\end{array}$ & $\begin{array}{l}3491.5 \\
\pm 490.3\end{array}$ & $\begin{array}{l}2218.0 \\
\pm 338.0\end{array}$ & $\begin{array}{l}2139.1 \\
\pm 375.3\end{array}$ & $\begin{array}{l}2313.2 \\
\pm 322.3\end{array}$ & $\begin{array}{l}2821.5 \\
\pm 768.7\end{array}$ & -0.12 \\
\hline $\mathrm{pH}$ & $6.2 \pm 0.2$ & $6.1 \pm 0.1$ & $6.1 \pm 0.1$ & $6.2 \pm 0.1$ & $6.3 \pm 0.1$ & $6.3 \pm 0.1$ & $6.4 \pm 0.1$ & $0.37 *$ \\
\hline $\begin{array}{l}\text { Osmolality } \\
(\mathrm{mOsm} / \mathrm{kg})\end{array}$ & $\begin{array}{r}400.3 \\
\pm 7.8\end{array}$ & $\begin{array}{l}441.5 \\
\pm 36.1\end{array}$ & $\begin{array}{l}433.8 \\
\pm 5.1\end{array}$ & $\begin{array}{l}463.6 \\
\pm 17.6 *\end{array}$ & $\begin{array}{l}449.5 \\
\pm 16.4\end{array}$ & $\begin{array}{l}484.6 \\
\pm 23.1 * *\end{array}$ & $\begin{array}{l}470.5 \\
\pm 17.2^{*}\end{array}$ & $0.38 * *$ \\
\hline MOT (\%) & $85.0 \pm 2.2$ & $70.0 \pm 4.1$ & $56.2 \pm 4.9^{*}$ & $29.5 \pm 9.2^{* * * k}$ & $44.4 \pm 10.6^{* *}$ & $41.0 \pm 7.5^{* *}$ & $29.6 \pm 9.1^{* * *}$ & $-0.45^{* *}$ \\
\hline PROG (\%) & $47.0 \pm 16.2$ & $44.0 \pm 4.0$ & $26.0 \pm 4.4$ & $9.8 \pm 4.3^{* * *}$ & $16.2 \pm 5.7^{* *}$ & $7.4 \pm 4.6^{* *}$ & $4.1 \pm 2.0^{* * *}$ & $-0.52^{* * *}$ \\
\hline HOST (\%) & $78.7 \pm 3.7$ & $69 \pm 6.3$ & $71.1 \pm 3.4$ & $65.9 \pm 7$ & $69.5 \pm 6.5$ & $63.4 \pm 8.1$ & $50.1 \pm 3.6$ & $-0.43^{* *}$ \\
\hline Abnormal forms (\%) & $16.7 \pm 1.5$ & $28.3 \pm 10.8$ & $35.6 \pm 4.8$ & $44.2 \pm 10.8$ & $35.8 \pm 4.1$ & $36.4 \pm 7.7$ & $55 \pm 6.7$ & $0.39 * *$ \\
\hline \multicolumn{9}{|l|}{ Cytoplasmic droplets } \\
\hline Proximal (\%) & $1.3 \pm 0.9$ & $3.3 \pm 2.8$ & $4.7 \pm 1.6$ & $11.8 \pm 4.8$ & $6.9 \pm 1.3$ & $15.4 \pm 3.4$ & $19.6 \pm 6.2$ & $0.43^{* *}$ \\
\hline Distal (\%) & $90.7 \pm 0.9$ & $82.7 \pm 8.0$ & $82.0 \pm 2.2$ & $70.9 \pm 9.9$ & $68.0 \pm 7.9$ & $65.4 \pm 6.5$ & $55.0 \pm 7.4$ & $-0.45^{* *}$ \\
\hline Viability & $74.2 \pm 3.5$ & $62.5 \pm 4.5$ & $65.5 \pm 6.5$ & $66.4 \pm 5.9$ & $53 \pm 12.5$ & $77.7 \pm 1.9$ & $40^{\mathrm{b}}$ & -0.26 \\
\hline Acrosomal damage & $4.8 \pm 0.9$ & $19 \pm 2$ & $22.3 \pm 6.7$ & $9.3 \pm 4.4$ & $26.8 \pm 8.6$ & $3.9 \pm 0.7$ & $41^{b}$ & 0.23 \\
\hline
\end{tabular}

MOT: Total motility, subjective; PROG: Progressive motility, subjective; HOST: Hypoosmotic swelling test; Viability: Proportion if propidium iodide negative cells; Acrosomal damage: Proportion of peanut agglutinin (PNA) positive cells.

a $\mathrm{PM}$ intervals refer to post-mortem time in $\mathrm{h}$ and follow the bracket rule: E.g., being $\mathrm{x}$ a number within a post-mortem interval, [6, 24 ] is equivalent to $6 \mathrm{~h} \leq \mathrm{x} \leq$ $24 \mathrm{~h}$ and $] 24,48$ ] is equivalent to $24 \mathrm{~h}<\mathrm{x} \leq 48 \mathrm{~h}$.

b Only one sample could be assessed.

were not significant for viability (membrane integrity) or acrosomal damage. The proportion of abnormal spermatozoa increased, mainly due to alterations in the flagellum (bent or coiled). The proportion of spermatozoa with proximal droplets increased as duration of post-mortem time lengthened, whereas the samples with distal droplets markedly decreased.

The values for CASA variables (Table 2 ) had a similar decreasing trend in the motility variables (Table 1). Not all samples could be analysed by CASA, therefore, the effects of the different post-mortem intervals with the [6, 24] h baseline did have a trend line as evidenced for the values of variables in Table 1 . Nevertheless, the values for all variables related to sperm kinetics and vigour (velocities, ALH, BCF) were negatively correlated with post-mortem time, whereas values for variables related to the shape of the trajectory (LIN, STR, WOB) were not affected.

With classification of the samples according to the sperm quality, three of five samples collected before $24 \mathrm{~h}$ post-mortem were considered to be of "high" quality, but samples collected at subsequent intervals were classified as being of "medium" quality (3/4 at $[24,48], 4 / 13$ at $[48,72]$ and only $1 / 10$ at $[96,144])$. Sperm quality values for none of the 11 samples collected at [72, 96] or of the 14 samples collected after $144 \mathrm{~h}$ were classified of being of "medium" quality. The association of post-mortem time with the number of "high" or "medium" quality samples collected at each interval was significant $(P=0.001$ and $P<0.001$, respectively).

Table 2

CASA parameters for samples collected from Cantabrian chamois epididymal spermatozoa in each time interval (mean \pm SEM); Last column $r$ shows the correlation coefficient of each parameter with the post-mortem time; Asterisks indicate $\left({ }^{*} P<0.05,{ }^{*} P<0.01\right.$, ${ }^{* * *} P<0.001$ ) of the effect of each post-mortem interval (baseline at $[6,24] \mathrm{h}$ ) and of the correlation coefficient $r$.

\begin{tabular}{|c|c|c|c|c|c|c|c|}
\hline PM intervals $(\mathrm{h})^{\mathrm{a}}$ & {$[6,24]$} & {$[24,48]$} & {$[48,72]$} & {$[72,96]$} & {$[96,144]$} & {$[144,216]$} & \\
\hline Analysed samples & 5 & 1 & 4 & 5 & 3 & 4 & $\mathrm{r}$ \\
\hline MOT (\%) & $81.4 \pm 0.8$ & 58.0 & $37.8 \pm 10.5^{*}$ & $25.4 \pm 13.5^{* * *}$ & $6.1 \pm 2.8^{* * *}$ & $37.6 \pm 9.8^{*}$ & $-0.49^{*}$ \\
\hline PROG (\%) & $34.8 \pm 12.7$ & 29.0 & $13.8 \pm 8.8$ & $8.4 \pm 4.5^{*}$ & $0.2 \pm 0.2^{* *}$ & $9.3 \pm 6.7$ & $-0.51^{*}$ \\
\hline $\operatorname{VAP}(\mu \mathrm{m} / \mathrm{s})$ & $78.9 \pm 12.7$ & - & $43.5 \pm 15.7$ & $28 \pm 13.7^{*}$ & $24.3 \pm 4.4^{*}$ & $30.8 \pm 12.2^{*}$ & $-0.52^{*}$ \\
\hline $\mathrm{VCL}(\mu \mathrm{m} / \mathrm{s})$ & $125.3 \pm 24.6$ & - & $59.5 \pm 15.7$ & $43 \pm 15.5^{*}$ & $38.7 \pm 7.8^{*}$ & $43.5 \pm 13.9^{* *}$ & $-0.58^{* *}$ \\
\hline VSL $(\mu \mathrm{m} / \mathrm{s})$ & $53.2 \pm 8$ & - & $34.2 \pm 15.3$ & $18.3 \pm 9 *$ & $13.3 \pm 3^{*}$ & $21.8 \pm 11.6^{*}$ & $-0.54^{*}$ \\
\hline LIN (\%) & $36.7 \pm 11.9$ & - & $35.5 \pm 13.4$ & $46.7 \pm 18.3$ & $43.0 \pm 7.0$ & $41.2 \pm 10$ & 0.07 \\
\hline STR (\%) & $69.8 \pm 8.9$ & - & $72.5 \pm 5.9$ & $64.7 \pm 13.6$ & $60.3 \pm 3.5$ & $60.2 \pm 8$ & -0.33 \\
\hline WOB (\%) & $65.7 \pm 6.6$ & - & $65.8 \pm 9.1$ & $60.3 \pm 13.2$ & $63 \pm 2.1$ & $65.5 \pm 7$ & -0.07 \\
\hline $\mathrm{ALH}(\mu \mathrm{m})$ & $4.4 \pm 0.3$ & - & $3.1 \pm 0.8$ & $2.4 \pm 0.8$ & $2.1 \pm 0.6^{*}$ & $2.4 \pm 0.7^{*}$ & $-0.52^{*}$ \\
\hline BCF (Hz) & $12.9 \pm 1.6$ & - & $6.6 \pm 1.5$ & $8.5 \pm 3$ & $8.6 \pm 3.6$ & $5.1 \pm 2.3^{*}$ & $-0.49^{*}$ \\
\hline
\end{tabular}

MOT: Total motility; PROG: Progressive motility; VAP: Average path velocity; VCL: Curvilinear path velocity; VSL: Straight path velocity; LIN: Linearity; STR: Straightness; WOB: Wobble; ALH: Amplitude of the lateral displacement of the sperm head; BCF: Beat-cross frequency.

a PM intervals refer to post-mortem time in $\mathrm{h}$ and follow the bracket rule: e.g., being $\mathrm{x}$ a number within a post-mortem interval, [6, 24 ] is equivalent to $6 \mathrm{~h} \leq \mathrm{x} \leq$ $24 \mathrm{~h}$ and $] 24,48]$ is equivalent to $24 \mathrm{~h}<\mathrm{x} \leq 48 \mathrm{~h}$. 
There was a decrease in values in thawed semen for most sperm quality variables (Tables 3 and 4).The probability, however, was only significant for the decrease in subjective motility $(P=0.042)$, HOS test reactivity $(P<0.001)$ and for the increase in reacted acrosomes $(P=0.049)$. The presence of cytoplasmic droplets was also different as the duration of post-mortem collection time increased (proximal $P=0.002$, distal $P=0.007$, total $P<0.001$ ). The lack of significance was due to the great variability among males, which is depicted in Fig. 1 for three parameters. In this figure, for HOS test reactivity (Fig. 1c) there was a trending for a general decrease that was quite homogeneous between males and time intervals. On the contrary, for subjective motility (Fig. 1a and b), there was a great heterogeneity for the trend of change observed after cryopreservation; very evident for progressivity (Fig. 1b), with an enhancement in many cases.

Interestingly, sperm freezability, as defined by the difference between post-thawed and fresh quality was improved with post-mortem time for some variables: PROG $(r=0.64, P=0.043)$, VCL $(r=0.72, P=0.042)$, ALH $(r=0.82, P=0.014)$, BCF $(r=0.71, P=0.047)$, abnormal forms $(r=-0.55, P=0.010)$, proximal cytoplasmic droplets $(r=-0.52, P=0.015)$ and damaged acrosomes $(r=-0.41, P=0.036)$.

\section{Discussion}

The results of the present study characterize the decrease of the quality of spermatozoa from Cantabric Chamois with post-mortem time. It is important to highlight that it might be possible to collect valuable and viable samples from this species for several days post-mortem, which could be invaluable for the establishment of a germplasm bank for this wild species.

Table 3

Characteristics of thawed Cantabrian chamois epididymal spermatozoa in each time interval (mean \pm SEM); Last column $r$ shows the correlation coefficient of each parameter with the post-mortem time; Asterisks indicates differences $\left({ }^{*} P<0.05, * * P<0.01\right)$ of the effect of each post-mortem interval (baseline at [6, 24] h) and of the correlation coefficient $r$.

\begin{tabular}{|c|c|c|c|c|c|c|c|c|}
\hline PM intervals (h) ${ }^{\mathrm{a}}$ & {$[6,24]$} & {$[24,48]$} & {$[48,72]$} & {$[72,96]$} & {$[96,144]$} & {$[144,216]$} & $>216$ & $r$ \\
\hline Analysed samples & 4 & 4 & 8 & 4 & 4 & 2 & 2 & \\
\hline MOT (\%) & $67.5 \pm 9.5$ & $75.0 \pm 2.0$ & $49.4 \pm 8.3$ & $51.2 \pm 14.8$ & $52.5 \pm 9.2$ & $13.5 \pm 6.5^{* *}$ & $35.0 \pm 5.0$ & $-0.46^{*}$ \\
\hline PROG (\%) & $35.0 \pm 18.8$ & $61.2 \pm 4.3$ & $25.6 \pm 8.3$ & $36.2 \pm 14.6$ & $16.2 \pm 4.7$ & $3.5 \pm 1.5$ & $6.0 \pm 4.0$ & $-0.43^{*}$ \\
\hline HOST (\%) & $58.5 \pm 0.5$ & $56 \pm 6.4$ & $54.0 \pm 4.1$ & $50.5 \pm 3.5$ & $47.0 \pm 5.1$ & $38.5 \pm 0.5$ & $41.0^{\ddagger}$ & $-0.49 *$ \\
\hline Abnormal (\%) & $23.5 \pm 0.5$ & $28.5 \pm 2.8$ & $27.9 \pm 1.3$ & $31.8 \pm 0.5$ & $27.2 \pm 3.4$ & $27.5 \pm 3.5$ & $30.0 \pm 0.0$ & 0.23 \\
\hline \multicolumn{9}{|l|}{ Citoplasmic droplets } \\
\hline Proximal (\%) & $1.0 \pm 1.0$ & $1.0 \pm 0.7$ & $0.4 \pm 0.4$ & $1.0 \pm 1.0$ & $4.0 \pm 1.5$ & $7.5 \pm 1.5$ & $4.0 \pm 4.0$ & $0.45^{*}$ \\
\hline Distal (\%) & $73.0 \pm 1.0$ & $67.0 \pm 10.1$ & $66.1 \pm 5.4$ & $66.0 \pm 3.1$ & $48.8 \pm 12.8$ & $50.5 \pm 9.5$ & $51.5 \pm 4.5$ & $-0.42 *$ \\
\hline Viability & $52.9 \pm 6.4$ & $65.8 \pm 3.1$ & $55.8 \pm 5.1$ & $62.2 \pm 6$ & $59.2 \pm 6.4$ & $40.5 \pm 16.5$ & $64.0^{\mathrm{b}}$ & -0.04 \\
\hline Acrosomal damage & $24.3 \pm 3.8$ & $21.8 \pm 2.9$ & $28.1 \pm 4.0$ & $23.0 \pm 6.0$ & $30.2 \pm 5.2$ & $31.5 \pm 9.5$ & $20.0^{\mathrm{b}}$ & 0.04 \\
\hline
\end{tabular}

MOT: Total motility, subjective; PROG: Progressive motility, subjective; HOST: Hypoosmotic swelling test; Viability: Proportion if propidium iodide negative cells; Acrosomal damage: Proportion of peanut agglutinin (PNA) positive cells.

a PM intervals refer to post-mortem time in $\mathrm{h}$ and follow the bracket rule: E.g., being $\mathrm{x}$ a number within a post-mortem interval, [6, 24] is equivalent to $6 \mathrm{~h} \leq \mathrm{x} \leq$ $24 \mathrm{~h}$ and $[24,48]$ is equivalent to $24 \mathrm{~h}<\mathrm{x} \leq 48 \mathrm{~h}$.

b Only one sample could be assessed.

Table 4

CASA variables for post-thawed Cantabrian chamois epididymal spermatozoa in each post-mortem time interval (mean \pm SEM); Last column $r$ shows the correlation coefficient of each parameter with the post-mortem time; Asterisks indicate differences $\left({ }^{*} P<0.05\right.$, ${ }^{* *} P<0.01$ ) of the effect of each post-mortem interval (baseline at $[6,24] \mathrm{h})$ and of the correlation coefficient $r$.

\begin{tabular}{|c|c|c|c|c|c|c|c|}
\hline $\mathrm{PM}$ intervals $(\mathrm{h})^{\mathrm{a}}$ & {$[6,24]$} & {$[24,48]$} & {$[48,72]$} & {$[72,96]$} & {$[96,144]$} & {$[144,216]$} & \\
\hline Analysed samples & 4 & 4 & 8 & 4 & 4 & 2 & $r$ \\
\hline MOT (\%) & $80.8 \pm 9.2$ & $70.5 \pm 2.7$ & $53.9 \pm 11.6$ & $56.8 \pm 10.3$ & $54.5 \pm 9.9$ & $10.5 \pm 5.5^{* *}$ & $-0.57^{* *}$ \\
\hline PROG (\%) & $29.9 \pm 10.9$ & $38.2 \pm 5.6$ & $22.2 \pm 6.8$ & $26.2 \pm 6.5$ & $13.0 \pm 4.8$ & $4.0 \pm 2.0$ & $-0.46^{*}$ \\
\hline $\mathrm{VAP}(\mu \mathrm{m} / \mathrm{s})$ & $82.2 \pm 8.1$ & $69.8 \pm 5.2$ & $61.5 \pm 5.2^{*}$ & $66.2 \pm 8.9$ & $61.8 \pm 4.6$ & $47 \pm 11^{* *}$ & $-0.50^{* * *}$ \\
\hline VCL $(\mu \mathrm{m} / \mathrm{s})$ & $119.2 \pm 23.3$ & $93.8 \pm 7.3$ & $87.6 \pm 7.0$ & $86.8 \pm 12.3$ & $81.8 \pm 7.6$ & $63.5 \pm 14.5^{*}$ & $-0.48^{*}$ \\
\hline VSL $(\mu \mathrm{m} / \mathrm{s})$ & $51.2 \pm 10.8$ & $56.5 \pm 7.1$ & $45.4 \pm 5.0$ & $49.2 \pm 7.9$ & $36.5 \pm 3.7$ & $31.0 \pm 7.0$ & $-0.40^{*}$ \\
\hline LIN (\%) & $45.2 \pm 11.2$ & $45.2 \pm 13.5$ & $51.8 \pm 2.2$ & $59.0 \pm 1.2$ & $46.8 \pm 4.8$ & $28.5 \pm 22.5$ & -0.25 \\
\hline STR (\%) & $59.8 \pm 10.9$ & $77.2 \pm 4.7^{*}$ & $67.5 \pm 2.9$ & $73.5 \pm 2.9$ & $59.5 \pm 4.1$ & $68.0 \pm 3.0$ & -0.08 \\
\hline WOB (\%) & $72.2 \pm 7$ & $74.2 \pm 0.6$ & $71.2 \pm 4.2$ & $76.8 \pm 2.8$ & $76.2 \pm 3.4$ & $73.5 \pm 0.5$ & 0.05 \\
\hline ALH $(\mu \mathrm{m})$ & $3.7 \pm 0.5$ & $5.2 \pm 0.4$ & $4.3 \pm 0.6$ & $4.3 \pm 0.8$ & $4.0 \pm 0.6$ & $2.4 \pm 1.4$ & -0.36 \\
\hline $\mathrm{BCF}(\mathrm{Hz})$ & $11.2 \pm 2.3$ & $10.7 \pm 1.3$ & $9.4 \pm 0.9$ & $9.2 \pm 1.8$ & $6.4 \pm 0.7^{*}$ & $7.2 \pm 0.3$ & $-0.41 *$ \\
\hline
\end{tabular}

MOT: Total motility; PROG: Progressive motility; VAP: Average path velocity; VCL: Curvilinear path velocity; VSL: Straight path velocity; LIN: Linearity; STR: Straightness; WOB: Wobble; ALH: Amplitude of the lateral displacement of the sperm head; BCF: Beat-cross frequency.

a $\mathrm{PM}$ intervals refer to post-mortem time in $\mathrm{h}$ and follow the bracket rule: e.g., being $\mathrm{x}$ a number within a post-mortem interval, [6, 24 ] is equivalent to $6 \mathrm{~h} \leq \mathrm{x} \leq$ $24 \mathrm{~h}$ and $[24,48]$ is equivalent to $24 \mathrm{~h}<\mathrm{x} \leq 48 \mathrm{~h}$ 


\section{a) Total motility (subjective)}

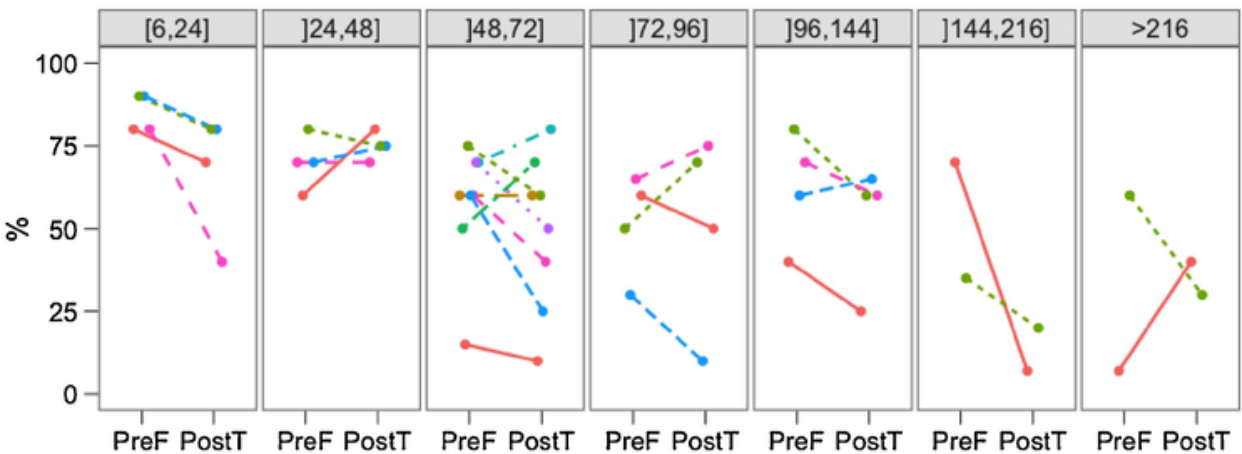

b) Progressive motility (subjective)

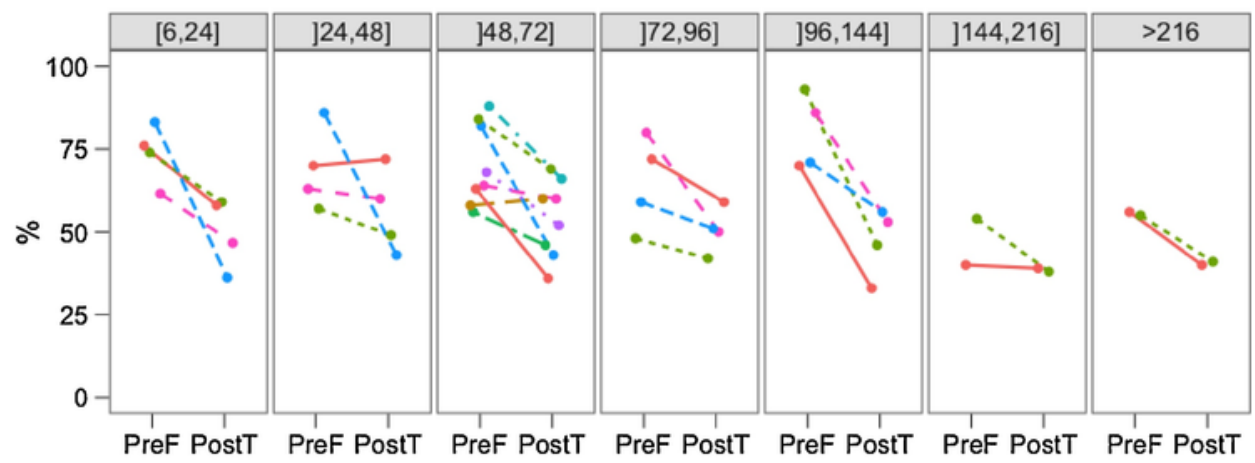

c) HOS test

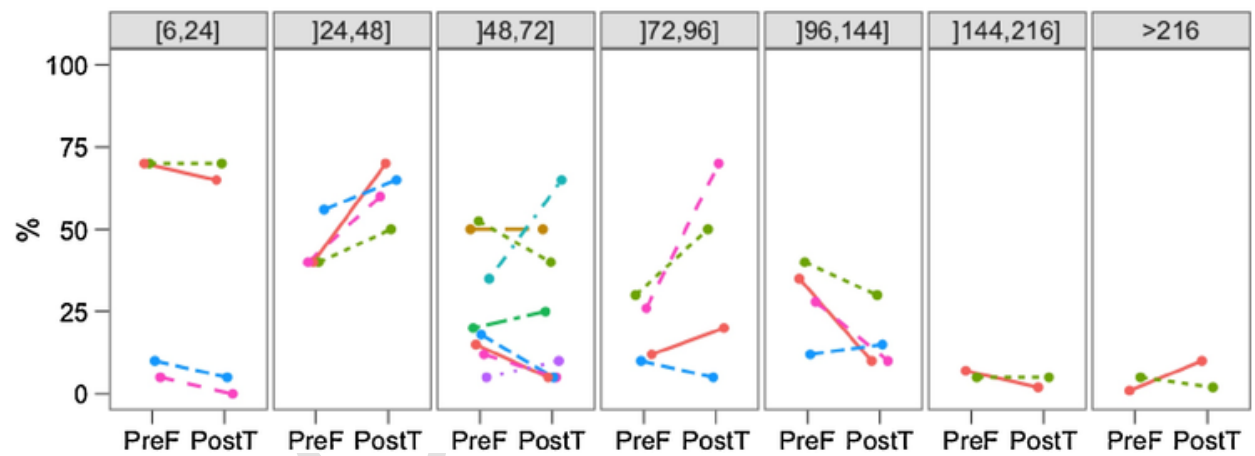

Fig. 1. Cryopreservation-induced changes in subjectively-assessed motility and HOS test parameters for Cantabrian chamois epididymal spermatozoa: Total motility (a), progressive motility (b) and hypoosmotic swelling test (HOS test) reactivity (c), segmented by post-mortem time intervals; Each colour and line type within each time interval represents an individual male (PreF: pre-freezing; PostT: post-thawing); Intervals refer to post-mortem time in h, and follow the bracket rule: E.g., being $\mathrm{x}$ a number within a post-mortem interval, $[6,24]$ is equivalent to $6 \mathrm{~h} \leq \mathrm{x} \leq 24 \mathrm{~h}$ and $] 24,48]$ is equivalent to $24 \mathrm{~h}<\mathrm{x} \leq 48 \mathrm{~h}$. Whereas motility variables showed a great variability regarding the amount and direction of change, HOS test reactivity presented always a negative change, in general with a similar effect.

In practice, the determination of which collection method to use is dependent on the animal status: artificial vagina is routinely used for farmed animals, electroejaculation is applied to untrained or difficult-to-collect domestic males (and in many occasions to wild animals combined with teleanesthesia), whereas post-mortem collection is a very convenient method for wild animals, especially when there is consideration of hunting programs. Although spermatozoa should be recovered as soon as possible after the death of the male, studies on the detrimental effects of post-mortem time on epididymal sperm viability indicate that acceptable quality can be achieved if the genitalia are kept refrigerated (Garde et al., 1998; Sankai et al., 2001; Yu and Leibo, 2002; Tamayo-Canul et al., 2011a).

The observed decrease of sperm quality could be due both to sperm ageing and tissue decomposition that starts shortly after the time of death. The decrease in sperm quality with an increasing interval between the death of the individual and collection of sperm 
might be due to a process of degeneration in spermatozoa during storage after death in the male genitalia. These results are consistent with those reported by Christian et al. (1993) and Garde et al. (1994) where there were similar findings in mice and ram semen, respectively.

In mice, Songsasen et al. (1998) described important histological changes in testes from $18 \mathrm{~h}$ post-mortem which led to the disruption of the epithelium. Similar changes have been detected in Sika deer epididymides several days post-mortem (Hishinuma et al., 2003), particularly after day 4 and 7, results that are consistent with those of the present study in terms of increase of both osmolality and $\mathrm{pH}$. In contrast, in some studies with mice (Mohammadzadeh et al, 2011) there was also the conclusion that spermatozoa could be stored for as long as 18 days inside the epididymis of mice when there was storage at $6{ }^{\circ} \mathrm{C}$. Whereas in the present experiment the testicles were refrigerated during storage, the period between the death of the animal and the refrigeration of the genitalia was variable and not entirely controlled by the researchers. This was an added source of variability in the experiment and should be taken into account when considering germplasm banking programs. Nevertheless, when there is consideration that the animals were hunted in mid-autumn when there were cold ambient temperatures in the sampling area, and that the gamekeepers provided the times of hunting and refrigeration, helping to reduce the influence of this interval in the overall sperm quality. Indeed, a significant effect of this time was not considered in a preliminary analysis of the data in the present study. These kind of uncertainties predate not only experimental approaches used in the present study, but also in any attempt to establish a germplasm bank from wild or hunted animals.

Chamois reproductive biology has not been studied in depth, apart from reports by Martínez-Pastor et al. (2005d) and from other previous studies of Abruzzi chamois (Carluccio et al, 2007). In a previous study (Martínez-Pastor et al., 2005d), there was comparison of some genitalia morphometric data and seminal parameters between breeding and non-breeding periods, with results being reported for testicular and cauda epididymis weights, and salvaged spermatozoa similar what occurred in the current results. In the present study, a substantial amount of results are consistent with those from a previous study with red and roe deer (Martínez-Pastor et al., 2005c). Similar to results in the previous study, there was a positive correlation between osmolality and $\mathrm{pH}$ with post-mortem time. Nevertheless, changes in $\mathrm{pH}$ were not significant even at advanced stages, suggesting there is a resilience of the buffering system inside the tubules. Considering the confirmed effect of osmolality and pH with sperm motility and metabolism (Gatti et al., 1993), the alterations of the physical environment likely have an important role in the overall loss of sperm quality.

Consistent with results in several studies (Hishinuma et al., 2003; Kikuchi et al., 1998; Yu and Leibo, 2002; Kaabi et al., 2003; Martínez-Pastor et al., 2005c; Fernandez-Santos et al., 2009; Tamayo-Canul et al., 2011a, b), total and progressive sperm motility were the parameters for which there was the greatest decrease. Values for both motility variables assessed subjectively and objectively (CASA) confirmed that there was a decrease in sperm viability as time post-mortem increased. A similar pattern of decrease in motility was detected in Sika (Hishinuma et al., 2003) and Iberian red (Martínez-Pastor et al., 2005c; Soler et al., 2003) deer, with a significant reduction of the motility from day 1 and 2 and then gradually until the end of the study period. Furthermore, there was no significant effect regarding sperm viability when there was comparison at different post-mortem times nor when there was assessment with correlation analysis. The classification of the samples according to quality indicated that the proportion of samples classified to be of low quality increased with post-mortem time, with only 1 of 35 of the samples from $72 \mathrm{~h}$ classified as having acceptable quality, with results being similar to the classifications with red and roe deer (Martínez-Pastor et al., 2005c).

Chamois epididymal spermatozoa had acceptable post-thawing quality in the present study; considering the initial quality and the conditions for the sample collection. As in the first report on epididymal sperm cryopreservation in this species, the results are promising, although extender or freezing optimization might be further enhanced (Fernández-Santos et al., 2007; Martínez-Pastor et al., 2006a,c; Santiago-Moreno et al., 2006). To the best of our knowledge, there is only one report on chamois semen cryopreservation semen obtained by TUMASG (Pradiee et al., 2016), in which two similar time periods were assessed. In the present study, post-thawing quality and freezability were greater compared to the semen obtained by TUMASG, probably because the exposure to seminal plasma induces changes in the sperm membrane that decrease sperm cell viability as a result of cryopreservation. Seminal plasma in the caprinae could have different effects depending on many factors (Cabrera et al., 2005; La Falci et al., 2002). In fact, in experiments with epididymal spermatozoa from red deer and seminal plasma supplementation there were differing results depending on its preparation and experimental conditions (Martínez-Pastor et al, 2006a).

Indeed, the epididymal spermatozoa had enhanced motility after extension, suggesting that the motility depression observed in freshly collected samples might be temporal and explaining apparently by the greater motility after storage or cryopreservation (Martínez-Pastor et al, 2005b, 2005c, 2006c). Furthermore, Martínez-Pastor et al. (2006b), comparing many freezing protocols, found there was similar sperm motility for both electroejaculated and epididymal samples after thawing, even though the epididymal spermatozoa had undergone refrigerated storage for about $20 \mathrm{~h}$, and possibly due to a sub-estimation of the sperm quality in freshly collected (and maybe motility-inhibited) samples. There were similar effects with chamois sperm, at least with many of the males. Whether this increase in the motility is caused by a dilution of the epididymal milieu or by a direct effect of the extender components, this remains to be evaluated in future studies.

Other quality parameters usually affected by post-mortem conditions are the HOS test response (membrane functionality) and acrosomal integrity. Calculating a ratio of its values before and after cryopreservation, there was a trend in the results of the HOS test for motility parameters, with a time-dependent reduction of the ratio $(30 \%-60 \%)$ for this parameter. It is hypothesized that the first challenge with sperm extension might be the induction of a non-permanent change in the membrane permeability, resulting in an increased number of midpiece and tail abnormalities. There is reversion in these changes during the cryopreservation procedure, possibly due to the osmotic challenges involved with this procedure, and for which epididymal spermatozoa might endure to a greater extent than ejaculated gametes (Tamayo-Canul et al., 2011a). This hypothesis is supported by the viability results in the pre- 
sent study, resembling previous observations that the values of this parameter did not decrease significantly irrespective of motility loss (Martínez-Pastor et al., 2005c, 2006a, 2006b). In fact, changes before and after cryopreservation were minimal for this parameter, indicating the resilience of the sperm membrane of epididymal spermatozoa to freezing-thawing (Martínez-Pastor et al., 2005b; Tamayo-Canul et al., 2011a).

In conclusion, there is variability of results in chamois epididymal samples as duration of the period post-mortem increases, and there was successful cryopreservation of these samples, even at advanced stages in post-mortem period. Results of the present study are highly valuable for establishing suitable strategies for the GRBs of this wild species. The threshold or limitations can be defined when there is storage of the genitalia prior to sperm collection to day 4 or 5 post-mortem, and at the same times there was no apparent negative effect of this post-mortem interval in the freezing capacity of the samples, which is a promising aspect for the utilization of the collected samples.

\section{Conflict of interest}

The authors state no conflict of interest.

\section{Acknowledgements}

The authors would like to thank Juan José Martínez, César Gómez, Juan Carlos Peral, the Territorial Service of Environmental Affairs of León, and the gamekeepers of the hunting reserves of Picos de Europa, Mampodre and Ancares (León, Spain) for their collaboration in the collection of the samples. F. Martínez-Pastor was supported by a PhD grant (The Ministry of Education, Culture and Sports, Spain) and by the Ramón y Cajal programme (The Spanish Ministry of Science and Innovation).

\section{References}

Bóveda, P., Esteso, M.C., Castaño, C., Toledano-Díaz, A., López-Sebastián, A., Muñiz, A., Prieto, P., Mejía, O., Ungerfeld, R., Santiago-Moreno, J., 2018. Slow and ultra-rapid freezing protocols for cryopreserving mouflon (Ovis musimon) and fallow deer (Dama dama) epididymal sperm. Anim. Reprod. Sci. 192 , $193-199$.

Cabrera, F., Gonzalez, F., Batista, M., Calero, P., Medrano, A., Gracia, A., 2005. The effect of removal of seminal plasma, egg yolk level and season on sperm freezability of canary buck (Capra hircus). Reprod. Domest. Anim. 40, 191-195.

Carluccio, A., Ponzio, P., Tosi, U., De Amicis, I., Robbe, D., Pennelli, M., Contri, A., 2007. Semen evaluation in the chamois of Abruzzi (Rupicapra pyrenaica ornata). Anim. Reprod. Sci. 97, 186-190.

Christian, C., Songsasen, N., Leibo, S.P., 1993. Presence of motile sperm in mice 24 hours post-mortem. Theriogenology $39,201$.

Fernández-Santos, M.R, Martínez-Pastor, F., García-Macías, V., Esteso, M.C., Soler, A.J., de Paz, P., Anel, L., Gardea, J.J., 2007. Extender osmolality and sugar supplementation exert a complex effect on the cryopreservation of Iberian red deer (Cervus elaphus hispanicus) epididymal spermatozoa. Theriogenology 67, 738-753.

Fernandez-Santos, M.R., Martínez-Pastor, F., Matias, D., Dominguez-Rebolledo, A.E., Esteso, M.C., Montoro, V., Garde, J.J., 2009. Effects of long-term chilled storage of red deer epididymides on DNA integrity and motility of thawed spermatozoa. Anim. Reprod. Sci. 111, 93-104.

Fernández-Santos, M.R., Soler, A.J., Ramón, M., Ros-Santaella, J.L., Maroto-Morales, A., García-Álvarez, O., Bisbal, A., Garde, J.J., Coloma, M.A., Santiago-Moreno, J., 2011. Effect of post-mortem time on post-thaw characteristics of Spanish ibex (Capra pyrenaica) spermatozoa. Anim. Reprod. Sci. 129, 56-66.

Foote, R., 2000. Fertilizing ability of epididymal sperm from dead animals. J. Androl. 21, 355.

Garde, J., Aguado, M.J., Pkrez-Guzmh, M.D., Montoro, V., Artiga, C., 1994. Determination of seminal quality of epididymal sperm from post-mortem rams. Biol. Reprod. 50,79 .

Garde, J., Ortiz, N., Garcia, A., Gallego, L., Landete, C.T., Lopez, A., 1998. Post-mortem assessment of sperm characteristics of the red deer during the breeding season. Arch. Androl. 41, 195-202.

Gatti, J., Chevrier, C., Paquignon, M., Dacheux, J., 1993. External ionic conditions, internal pH and motility of ram and boar spermatozoa. J. Reprod. Fertil. 98, 439-449.

Hishinuma, M., Suzuki, K., Sekine, J., 2003. Recovery and cryopreservation of sika deer (Cervus nippon) spermatozoa from epididymides stored at $4{ }^{\circ} \mathrm{C}$. Theriogenology 59, 813-820.

Holt, W.V., Pickard, A.R., 1999. Role of reproductive technologies and genetic resource banks in animal conservation. Rev. Reprod. 4, $143-150$.

Kaabi, M., de Paz, P., Álvarez, M., Anel, E., Boixo, J., Rouissic, H., Herráez, P., Anel, L., 2003. Effect of epididymis handling conditions on the quality of ram spermatozoa recovered post-mortem. Theriogenology 56, 1249-1259.

Kikuchi, K., Nagai, T., Kashiwazaki, N., Ikeda, H., Noguchi, J., Shimada, A., Soloy, E., Kaneko, H., 1998. Cryopreservation and ensuing in vitro fertilization ability of boar spermatozoa from epididymides stored at $4{ }^{\circ} \mathrm{C}$. Theriogenology 50, 615-623.

La Falci, V.S, Tortorella, H., Rodrigues, J.L., Brandelli, A., 2002. Seasonal variation of goat seminal plasma proteins. Theriogenology 57, 1035-1048.

Marco, I., Lopez-Olvera, J.R., Rosell, R., Vidal, E., Hurtado, A., Juste, R., Pumarola, M., Lavin, S., 2007. Severe outbreak of disease in the southern chamois (Rupicapra pyrenaica) associated with border disease virus infection. Vet. Microbiol. 120, 33-41.

Marco, I., Rosell, R., Cabezón, O., Mentaberre, G., Casas, E., Velarde, R., López-Olvera, J.R., Hurtado, A., Lavín, S., 2008. Epidemiological study of border disease virus infection in Southern chamois (Rupicapra pyrenaica) after an outbreak of disease in the Pyrenees (NE Spain). Vet. Microbiol. 127, $29-38$.

Martínez, A.F., Martínez-Pastor, F., Álvarez, M., Fernández-Santos, M.R., Esteso, M.C., de Paz, P., Garde, J.J., Anel, L., 2008. Sperm parameters on Iberian red deer: electroejaculation and post-mortem collection. Theriogenology 70, 216-226.

Martínez-Pastor, F., Díaz-Corujo, A.R., Anel, E., Herráez, P., Anel, L., de Paz, P., 2005. Post mortem time and season alter subpopulation characteristics of Iberian red deer epididymal sperm. Theriogenology 64, 958-974.

Martínez-Pas

tor et

al.,

2005b. F. Martínez-Pastor, V. Garcia-Macias, M. Álvarez, P. Herráez, L. Anel, P. de Paz, Sperm subpopulations in Iberian red deer epididymal sperm and their changes through the cryopreservation process, Biol. Reprod. 72 (2005)b, 316-327.

Martínez-Pastor, F., Guerra, C., Kaabi, M., Díaz, A.R., Anel, E., Herráez, P., de Paz, P., Anel, L., 2005. Decay of sperm obtained from epididymides of wild ruminants depending on post-mortem time. Theriogenology 63, 24-40.

Martínez-Pastor, F., Guerra, C., Kaabi, M., Garcia-Macias, V., de Paz, P., Álvarez, M., Herráez, P., Anel, L., 2005. Season effect on genitalia and epididymal sperm from Iberian red deer, roe deer and Cantabrian chamois. Theriogenology 63, 1857-1875.

Martínez-Pastor, F., Anel, L., Guerra, C., Álvarez, M., Soler, A.J., Garde, J.J., Chamorro, C., de Paz, P., 2006. Seminal plasma improves cryopreservation of Iberian red deer epididymal sperm. Theriogenology 66, 1847-1856. 
Martínez-Pastor, F., Garcia-Macias, V., Álvarez, M., Chamorro, C., Herráez, P., de Paz, P., Anel, L., 2006. Comparison of two methods for obtaining spermatozoa from the cauda epididymis of Iberian red deer. Theriogenology 65, 471-485.

Martínez-Pastor, F., Martínez, F., Garcia-Macias, V., Esteso, M., Anel, E., Fernández-Santos, M.R., Soler, A.J., de Paz, P., Garde, J., Anel, L., 2006. A pilot study on post-thawing quality of Iberian red deer spermatozoa (epididymal and electroejaculated) depending on glycerol concentration and extender osmolality. Theriogenology 66, 1165-1172.

Mohammadzadeh, S., Maksudov, G.Y., Doronin, Y.K., 2011. Survival of spermatozoa in the genital tract of mice post mortem. Dokl. Biol. Sci. 436, 62.

Pradiee, J., O’Briena, E., Esteso, M.C., Castaño, C., Toledano-Díaz, A., Lopez-Sebastián, A., Marcos-Beltrán, J.L., Vega, R.S., Guillamón, F.G., Martínez-Nevado, E., Guerra, R., 2016. Effect of shortening the prefreezing equilibration time with glycerol on the quality of chamois (Rupicapra pyrenaica), ibex (Capra pyrenaica), mouflon (Ovis musimon) and aoudad (Ammotragus lervia) ejaculates. Anim. Reprod. Sci. 171, 121-128.

Prieto, M.T., Sanchez-Calabuig, M.J., Hildebrandt, T.B., Santiago-Moreno, J., Saragusty, J., 2014. Sperm cryopreservation in wild animals. Eur. J. Wildl. Res. 60, 851-864.

Salamon, S., Maxwell, W.M., 2000. Storage of ram semen. Anim. Reprod. Sci. 62, 77-111.

Sankai, T., Tsuchiya, H., Ogonuki, N., 2001. Short-term nonfrozen storage of mouse epididymal spermatozoa. Theriogenology 55, $1759-1768$.

Santiago-Moreno, J., Toledano-Díaz, A., Pulido-Pastor, A., Dorado, J., Gómez-Brunet, A., López-Sebastián, A., 2006. Effect of egg yolk concentration on cryopreserving Spanish ibex (Capra pyrenaica) epididymal spermatozoa. Theriogenology 66, 1219-1226.

Soler, A.J., Garde, J.J., 2003. Relationship between the characteristics of epididymal red deer spermatozoa and penetrability into zona-free hamster ova. J. Androl. 24 393-400.

Soler, A., Pérez-Guzmán, M., Garde, J.J., 2003. Storage of red deer epididymides for four days at $5{ }^{\circ} \mathrm{C}$ : effects on sperm motility, viability, and morphological integrity. J. Exp. Zool. 295, 188-199.

Songsasen, N., Tong, J., Leibo, S., 1998. Birth of live mice derived by in vitro fertilization with spermatozoa retrieved up to twenty-four hours after death. J. Exp. Zool. 280, 189-196.

Tamayo-Canul, J., Álvarez, M., López-Urueña, E., Nicolas, M., Martínez-Pastor, F., Anel, E., Anel, L., de Paz, P., 2011. Undiluted or extended storage of ram epididymal spermatozoa as alternatives to refrigerating the whole epididymides. Anim. Reprod. Sci. 126, 76-82.

Tamayo-Canul, J., Álvarez, M., Mata-Campuzano, M., Álvarez-Rodríguez, M., de Paz, P., Anel, L., Martínez-Pastor, F., 2011. Effect of storage method and extender osmolality in the quality of cryopreserved epididymal ram spermatozoa. Anim. Reprod. Sci. 129, $188-199$.

Turner, T., 1995. On the epididymis and its role in the development of the fertile ejaculate. J. Androl. 16, 292-298.

Yu, I., Leibo, S., 2002. Recovery of motile, membrane-intact spermatozoa from canine epididymides stored for 8 days at $4{ }^{\circ} \mathrm{C}$. Theriogenology $57,1179-1190$. 